\title{
Ecos y remembranzas: trazas precolombinas en el arte contemporáneo*
}

\author{
Bruno Jara Ahumada \\ Universidad de Santiago de Chile \\ cosas.yme@gmail.com
}

\begin{abstract}
Resumen
El artículo pretende encontrar ecos y resistencias tácitas del acervo precolombino en el arte reciente chileno. Entendidas como un material reconstructivo de la historia latinoamericana, las objetivaciones del "Otro" fueron destituidas mediante una serie de estrategias que instaló Occidente durante la Conquista. Para evidenciarlas, trazaremos una cadena de resignificaciones visuales: a partir de un soporte prehispánico, delinearemos matrices comparativas, con el objeto de identificar remembranzas, signos en común o paralelos metodológicos en el trabajo de Magdalena Atria y el colectivo Museo Internacional de Chile ( $\mathrm{MICH})$.
\end{abstract}

Palabras clave

Arte precolombino, conquista de América, memoria cultural, arte contemporáneo, resignificación.

\section{Echoes and remembrances: pre-Columbian traces in contemporary art}

\begin{abstract}
This article aims to identify pre-Columbian echoes and their subtle forms of resistance in contemporary Chilean art. Objectifications of the "Other" during the Conquest are seen as a reconstructive material of Latin American history and we attempt to reveal Western strategies to dismantle these objectifications. In order to do this, we will draw a chain of visual resignifications from a pre-Hispanic milieu. We will delineate a comparative framework to identify remembrances, common signs or methodological parallels in the work of Magdalena Atria and the art group Museo Internacional de Chile (MICH).
\end{abstract}

Keywords

Pre-Columbian art, conquest of America, cultural memory, contemporary art, resignification.

* Recibido: 15 de marzo de 2017/ Aceptado: 27 de noviembre. 


\section{Ecos e lembranças: vestígios pré-colombianos na arte contemporânea}

Resumo

O artigo pretende encontrar ecos e resistências não ditas da coleção pré-colombiana na arte recente chilena. Visto como um material reconstrutivo da história latinoamericana, será feita uma tentativa de demonstrar as estratégias que o Ocidente instalou para descartar as objetivações do Outro durante a Conquista. Para fazer isso, vamos desenhar uma cadeia de resignificados visuais: de um suporte pré-hispânico, delinearemos matrizes comparativas para identificar lembranças, sinais comuns ou paralelos metodológicos no trabalho de Magdalena Atria e do coletivo Museo Internacional de Chile.

\section{Palavras-chave}

Arte pré-colombiana, conquista da América, memória cultural, arte contemporânea, resignificação. 


\section{Introducción}

Las memorias son transgredidas a partir de una incisión que bifurca los sentidos históricos hacia una retícula de fragmentos dispares y heterogéneos: esferas de tiempo concentradas por el trauma y la dolencia. Son tejidas, en consecuencia, numerosas memorias que compiten en simultáneo por adjudicarse el reconocimiento público de las formas que estructuran su pasado. Esta pluralidad de mecanismos cruzados nos obliga a pensar en una memoria multidireccional (Rothberg, 2009), es decir, en la interacción dinámica entre los distintos recuerdos que confluyen en el presente y que trabajan en conjunto por modular nuevas versiones para comprender la historia. Vista de este modo, la conquista de América todavía supone un conflicto de memorias enfrentadas al momento de conciliar los estragos de la dominación y el genocidio.

Una de las posibles entradas para abordar este dilema subyace en la constitución misma del continente como negatividad de aquello que no alcanzó a ser reconocible, sino únicamente subsumible a la monstruosidad. Mabel Moraña considera que "América será, desde su aparición en el horizonte europeo, el afuera constitutivo de la modernidad, el lugar donde lo primitivo y lo arcaico tienen su morada, como contrapartidas del progreso y de la civilización del Viejo Mundo" (2014: 24). A partir de este principio re-fundacional, Europa escenificó un verdadero proceso de desarticulación simbólica: recuperando lo planteado por Serge Gruzinski, las expediciones implementaron una estrategia que quiso extirpar cada traza que no se correspondiera con los lineamientos de la corona española y que, en última instancia, borroneara las siluetas de la barbarie: "El Occidente proyectó sobre la América India unas categorías y unas redes para comprenderla, dominarla y aculturarla" (1994: 16). Dentro de estas categorías, el arte negó la preexistencia de representaciones dignas de ser catalogadas como tal. Atravesadas por una compleja red de significaciones sociales y simbólicas, las objetivaciones culturales de la América India implicaron un obstáculo que se opuso discursivamente a los preceptos artísticos todavía incipientes de la Europa renacentista. Bajo este prisma, el conquistador propició la supresión de los imaginarios indígenas, pretendiendo erradicar las incongruencias entre los dos acervos con el fin de imponer su visión unívoca de la cultura. En este sentido, el "arte nuevo" conllevó la descontextualización y el adoctrinamiento político del imaginario precedente, a través de las imágenes ajenas que fueron introducidas al continente (Gruzinski, 1994).

Tras este panorama, el arte precolombino eclipsa una pugna naturalizada de memorias; la conjunción de términos congela una perspectiva unidireccional de las expresiones prehispánicas: se nos ofrece una versión paupérrima de la imaginería, estancada en una tradición estática, condenada al olvido, y cuya 
reconstrucción en las artes contemporáneas apenas asociamos con la referencialidad. Si atendemos a los lineamientos de Ticio Escobar, en tanto que el término "arte" demanda una revisión crítica de su imposición hegemónica -cuyo discurso inicial pretendió absolutizar las formas artísticas en las que Europa se creyó representada y justificada (2008: 20)- ¿es posible aún descubrir ecos auténticos o gestos propios del acervo precolombino más allá del circuito cultural indígena?

Sostengo que, en efecto, y a pesar de la irrenunciable instauración del arte y sus estatutos, las significaciones simbólicas y sociales de las formaciones autóctonas todavía son rastreables tanto en el arte indígena como en el arte no-indígena contemporáneo. No obstante, pese a que lo anterior no implica ninguna novedad, mantengo la hipótesis de que esta remembranza es tanto o más rica en la medida en que dichos paralelismos no incumben necesariamente a rescates explícitos, reproducciones $u$ homenajes. Por el contrario, pienso que el valor de estos ecos se realza cuando son los propósitos o los procedimientos de la representación aquellos que se asemejan o tienden a coincidir ${ }^{1}$. Así, prefiero levantar una lectura que sea capaz de valorizar ciertas propuestas contemporáneas como reconfiguraciones tácitas del espectro precolombino, o bien como aproximaciones intuitivas hacia una misma resolución. Con esto no pretendo desestimar las formulaciones directas que hoy existen sobre el tema, ni tampoco cuestionar su legitimidad o su relevancia, sino más bien dirigir el campo de visión hacia las evocaciones menos obvias.

Para ello, iniciaremos este estudio delimitando qué entendemos por memoria cultural e imaginario social. Luego, categorizaremos la complexión del arte europeo al momento del arribo con el objeto de elaborar una directriz comparativa. Para cerrar, presentaremos una cadena de resignificaciones visuales que nos permitirá desmarañar los sentidos remanentes de las representaciones escogidas: a partir de los signos de la cerámica chilena prehispánica, buscaremos su posible resonancia dentro de dos obras recientes. Así, pondremos énfasis en la abstracción geométrica, examinando cómo se efectuó un desplazamiento de los valores de la imaginería oriunda, reduciendo su campo de acción tan sólo a la variable estética.

\section{Memoria cultural e imaginario social}

Previamente nos hemos referido al arte precolombino como un conjunto que yace atravesado por memorias en pugna. A partir de los aportes de Maurice Halbwachs, la memoria es comprendida como el proceso colectivo que ejecuta un grupo con el propósito de recomponer su pasado en su presente común. Dicha

\footnotetext{
${ }^{1}$ Autoría plural o anónima, representación de intangibles, funciones socio-religiosas, entre otros
} 
reconstrucción afianza un cuadro de semejanzas (1998: 219) que opera mediante marcaciones históricas precedentes, es decir, recuerdos y experiencias heredadas en la continuidad generacional del grupo. Para subvertir el deterioro de estas narraciones, la memoria se materializa en objetivaciones específicas que dan cuerpo a la memoria cultural, la cual, según Jan Asmman y John Czaplicka, se identifica por la trascendencia o esa distancia que mantiene con la memoria cotidiana o comunicacional (everyday memory). La memoria cultural, en cambio, tiene un punto fijo: su horizonte no cambia con el paso del tiempo (1995: 129). Las objetivaciones de la memoria cultural-representaciones en general- adscriben una suerte de energía mnémica capaz de abstraernos hacia dichos puntos de anclaje (fixed points), responsables de asentar su horizonte referencial. Estas franjas temporales, en tanto, quedan selladas tras acontecimientos que resquebrajan el acontecer histórico. En nuestro contexto, la violencia fue la clave que fijó a la Conquista, irremediablemente, en el centro de los conflictos memoriosos nacidos del Descubrimiento. Aquí es pertinente rescatar los aportes de Isabel Cruz:

Existe en general consenso entre los actuales historiadores para estimar que la Conquista es un tajo, más aún un trauma en la historia de los pueblos americanos: interrumpe su curso, quiebra su autonomía y altera su sentido. Pero es preciso recalcar que no significa, como se creyó en una época, la extinción de su identidad (1986: 23).

En efecto, a pesar de que la Conquista trastocó la cotidianidad del Nuevo Mundo de manera declarativa, la autora señala que la identidad prehispánica logró persistir mediante las concreciones culturales de las cuales se sirvió para reacomodar el presente. Esto, debido a que todo grupo fundamenta su conciencia de unidad y especificidad en base a dicho patrimonio: desarrolla impulsos formativos y normativos a partir de él (Asmman \& Czaplicka, 1995: 128). Vale decir, mediante la reactivación de las formas culturales, los grupos alternos afectados por la dominación consiguieron recomponer parcialmente el imaginario que les precedió y les instituye?

En suma, los repertorios de la memoria cultural ayudan a entretejer una imaginación social colectiva. Siguiendo las propuestas teóricas de Cornelius Castoriadis, por imaginario colectivo comprendemos la concepción global de objetivaciones o formas de aquello que los sujetos pertenecientes a cierto grupo entienden por realidad, sentido común o racionalidad, dentro de una sociedad histórica y espacialmente determinada (1997). Así, la colectividad es una totalidad cohesionada por las instituciones sociales -como el lenguaje, las normas y la familia- y por las significaciones que éstas portan (4). Finalmente, el imaginario instituye toda práctica pensable y decible de una sociedad como condición intrínseca a cualquiera

\footnotetext{
${ }^{2}$ Con esto no quiero dibujar una propuesta reductiva de la identidad latinoamericana. Señalar que los pueblos prehispánicos mantuvieron su unidad intacta, en ningún caso.
} 
de sus expresiones, e incluso funda los contornos de la sociedad misma que las piensa.

Resumiendo, contamos con un acervo de objetivaciones culturales que operan como medios capaces de corporeizar y perpetuar la memoria colectiva de los pueblos prehispánicos. Perturbados por la violencia y el horror, su continuidad histórica se torció y fraccionó en puntos de anclaje apoyados en un horizonte temporal siempre fijo, a los que podemos regresar mediante la reactivación de los productos de la memoria cultural. Representaciones que, en sumatoria, instituyen los modos efectivos y actuantes en los que la América prehispánica concebía su imaginación y pensaba su autoimagen. Una identidad, en definitiva, que se vio forzada a reactualizar y recrear el imaginario social con en cual estructuraba su pensamiento y, por tanto, las siluetas de cada una de sus representaciones.

\section{Apuntes sobre un concepto}

Si asumimos que los objetos se han transformado en un campo de disputa, pues representan la prueba sólida de una historia de vida y del capital cultural de una comunidad (Gallardo, 2016: 18), rescatar trazas prehispánicas en el arte contemporáneo se vuelve pertinente: a través de las resonancias afirmamos que aún, pese a los siglos, cultivamos aproximaciones artísticas semejantes. Por eso, más allá de enfrentar las distintas tipologías que derivan del conjunto autóctono ${ }^{3}$, me interesa tejer lineamientos comparativos y funcionales para diferenciar el acervo prehispánico de la concepción del arte europeo, según el contexto histórico que nos concierne.

Lo primero que debemos acotar es que, hacia 1492, la idea del arte todavía no terminaba de cuajar. Según Lourdes Méndez, recién en el Romanticismo se terminó de legitimar al artista moderno, mientras que, en simultáneo, aparecieron las categorías de salvaje, bárbaro y primitivo para clasificar las inscripciones del Otro (2006: 27). Estos objetos, no obstante, despertaron interés histórico, por lo que fueron vinculados con la antropología y no con el arte (28). Dicha catalogación duró por lo menos hasta el siglo XX y desatendió tanto a las formas prehispánicas como a las objetivaciones de los grupos sobrevivientes: "(en la Colonia) ningún creador o creadora indígena podía considerarse como artistas, ni sus obras como obras de arte" (28). Por otra parte, Larry Shiner acusa que la historia cultural trasladó retroactivamente el estatuto del arte moderno hacia el pasado, incluso cuando su consagración significó una ruptura que se produjo en el siglo XVII

\footnotetext{
${ }^{3}$ Arte prehispánico, arte indígena, arte popular, arte con influencia indígena, etc.
} 
(2004). A su vez, Wladyslaw Tatarkiewicz describe el concepto 4 como una epistemología indeterminada que problematiza la categorización de los objetos que pertenecen a su alcance.

Ahora bien, hacia fines del siglo XV el arte todavía arrastraba sus concepciones previas ${ }^{5}$, en las que "significaba destreza, a saber, la destreza que se requería para construir un objeto" (Tatarkiewicz, 2001: 39). Desde la Antigüedad, cualquier oficio implicaba una maestría particular; por tanto, cabía dentro de la nominación general de las "artes". Estas pericias se basaban en el conocimiento de unas técnicas, por lo que "no existía ningún arte sin reglas, sin preceptos" (Ibid.). A la vez, tampoco se manejaba un concepto para designar al arte bello, por lo cual las estatuas, los poemas y las obras musicales eran tratados como elementos que servían a propósitos particulares, más que como objetos que valían por ellos mismos (Shiner, 2004: 42). Esta consideración se mantuvo en el Medioevo y todavía en el Renacimiento, de modo que las artes siguieron operando bajo el sistema del mecenazgo/patronazgo, según el cual las obras estaban dedicadas a un público, un lugar o una función específicas (42). El artista no era autónomo ni perseguía impulsos afectivos: su labor enredaba la estética personal con los propósitos del mecenas y, en varios casos, imbricó la investigación científica. Finalmente, el "artista" -o "artífice" como se llamaba con frecuencia (73) - era el sujeto capaz de manejar la totalidad de técnicas relativas a un campo al momernto de concretar una determinada objetivación cultural.

Continuando, en el Renacimiento tardío se acuñaron conceptos para distanciar al artesano del artista, aceptando que la concreción de objetos domésticos en ningún caso se correspondía con el desarrollo de una pintura (Tatarkiewicz, 2001: 44). En consecuencia, la figura del artista como creador individual y hacedor de un conocimiento experto se intensificó a propósito de un sentido estético que preponderó por sobre la utilidad de las artes menores ${ }^{6}$. "La belleza, en el Renacimiento, comenzó a valorarse más y a jugar un rol en la vida que no había tenido desde los tiempos antiguos" (44). A partir de ahí, los oficios manuales y las ciencias se apartaron de aquellas disciplinas que más tarde se agruparían bajo la denominación de "bellas artes". Oposiciones como lo útil y lo bello; lo artístico y lo estético; la forma y el contenido; el arte y la sociedad, fueron utilizadas por los artífices para codificar y revalorizar sus prácticas: "El ideal de los notables artistas

\footnotetext{
${ }^{4} \mathrm{Me}$ abstendré de perfilar los antecedentes básicos que nos permitirán comprender al arte de los siglos XV y XVI. Para un desarrollo acabado de esta genealogía, ver Shiner (2004) y Tatarkiewicz (2001).

${ }^{5}$ Me refiero a las primeras nociones del arte como "ars" (latín) equivalentes a "téchne" (griego) o técnica.

${ }^{6}$ La categorización de "artes menores" antecede una separación entre las "artes liberales" y las "artes vulgares o mecánicas": las primeras correspondían al conjunto vinculado al ejercicio mental, mientras que las segundas se relacionaban con el esfuerzo físico y los oficios manuales.
} 
del Renacimiento fue fortalecer las leyes que regían sus trabajos, calcular sus obras con precisión matemática" (44). La proporción divina y la perspectiva fueron ejemplos de este rigor crítico, aplicado según la consigna del espíritu y la representación alegórica de los sentimientos más nobles, y unificadas, entre otros, por la belleza y la estética mimética que caracterizaron la época.

En resumen, el arte es un concepto tardío y atemporal a la Conquista, pero existieron preceptos cercanos a la idea del arte moderno durante el Renacimiento. Si bien estas peculiaridades merecen una mayor detención, estamos en condiciones de generar la siguiente matriz analítica: (1) el arte del Renacimiento mantuvo la noción del arte como técnica y destreza; (2) las destrezas del artista estaban condicionadas por las reglas propias a determinada experticia; (3) no obstante, el artista, en cuanto a destrezas únicas y facultades individuales, se diferenció del artesano, cuyas prácticas se relegaron a los oficios; (4) esta oposición se alcanzó mediante un proceso de precisión técnica-conceptual, en el cual se adoctrinaron las prácticas artísticas mayores dentro de un estatuto previo al de las bellas artes; (5) dicho estrato supuso la instauración de categorías nuevas capaces de diferenciar al campo; (6) así, el artista del Renacimiento se encargó de representar las nociones más nobles del espíritu mediante códigos como la proporción, la mímesis y la perspectiva. Una vez dibujado este esquema, contamos con un marco referencial apto para poder contrastar los imaginarios sociales y las objetivaciones culturales entre el Viejo y el Nuevo Mundo.

\section{Ecos y remembranzas}

Grosso modo, las concreciones prehispánicas fueron despreciadas luego de intentar adecuarlas al canon occidental (Escobar, 2013). El conquistador evaluó la otredad material según los parámetros artísticos de su época, separando el valor estético del valor artístico ${ }^{7}$; de modo tal que, desplazado el significante de su significado, la imaginería precolombina sufrió una fuga de las virtudes sociales que le fundaron ${ }^{8}$. La objetivación quedó reducida a una imagen, la cual no cuadró con la estética europea. Para Mabel Moraña aquí subyace un punto crítico:

Si el alfabeto se impone como una violencia civilizadora sobre las culturas orales, los sistemas gráficos prehispánicos y las lenguas vernáculas, la imagen europea, que se corresponde con una epistemología ajena al mundo americano, va construyendo una

\footnotetext{
${ }^{7}$ Para Ticio Escobar, lo estético refiere al momento perceptivo y sensible: las maniobras formales que recaen sobre el objeto. Mientras, lo artístico se entiende como "aquello que deviene de la forma" o los efectos estéticos que buscan intensificar la experiencia de lo real y movilizar el sentido, tras una sensación de "extrañamiento".

${ }^{8}$ Esta división desconoce que la forma y el contenido yacen enredados en un tejido social que las instituye tanto como las significa. Separarlas aniquila el sentido mismo del objeto.
} 
verdadera red conceptual e ideológica sobre los dominados, cuya visión del mundo es considerada irreverente y pecaminosa (2014: 29).

Fue en el plano de lo visual donde se maquinaron las oportunidades efectivas de supremacía. El europeo ofició diversas martingalas de resignificación visual a propósito de dos intenciones claras: en primer lugar, la Conquista, en términos de capital y tierra; en segundo lugar, la evangelización. Mientras la conquista militar optó por la sustracción de los símbolos prehispánicos y el genocidio, la conquista religiosa exigió la sustitución de los imaginarios autóctonos por los emblemas cristianos (Gruzinski, 1994). En su perspectiva, el europeo "intenta salvar al indio e incorporarlo a la verdadera fe demoliendo sus ídolos y sus creencias" (Cruz, 1986: 24). Teniendo esto en mente, el arte infiltrado en el continente cumplió funciones de guerra: "Lo que hoy vemos como el arte y la arquitectura indígenas fueron destruidos, puesto que las imágenes se veían como 'ídolos' y la arquitectura como la 'casa de los ídolos'” (Gamboa, 1995: 80).

Otro factor que jugó en contra del patrimonio autóctono fue la indeterminación técnica -acepción básica de las artes europeas- mediante las que fueron producidas estas formas. Desposeídas de una clasificación concreta -ni pintura, ni escultura, ni instrumento, ni artesanía-, Europa no logró identificarse con estas formulaciones confusas que pasó a fichar como demoniacas, inexpresivas o materialmente poco valiosas, y coordinó relatos míticos que omitieron dicha incongruencia con el fin de validar su versión hermética del arte. Retomando a Ticio Escobar, todos esos gestos y objetos precolombinos, e incluso los del arte indígena reciente, antes que apelar a la fruición estética, buscan reforzar, mediante otra idea de belleza, significados sociales que crecen mucho más allá de los terrenos del arte como lo entendemos desde Europa (2013: 6). Asimismo, el autor delata algunos lineamientos que mantuvo el opresor para fortalecer el mito de la inexistencia del arte en la América prehispánica:

Es que, por un lado, la acusada tendencia a la abstracción geométrica de muchos signos parece sugerir la mera intención ornamental de formas graciosas, exentas de responsabilidades simbólicas, mientras que, por otro, el peso abrumador de ciertos contenidos socioculturales y la rotunda presencia de funciones utilitarias parecen aplastar la forma (2008: 34).

Apelando a una ornamentación arbitraria, una representación que rehusaba la mímesis y, por otra parte, repudiando el valor utilitario o social de esas formas, Occidente fundó una narrativa capaz de soportar las discrepancias y aplanar las diferencias existentes entre ambos acervos. $Y$ es que la diversidad expresiva del arte precolombino superaba en magnitud al europeo, sobre todo si consideramos que su tradición arrastraba alrededor de cincuenta siglos (Gamboa, 1995: 78): 
desde las primeras manifestaciones artísticas en ajuares funerarios ${ }^{9}$ (Sánchez, 1989), pasando por la síntesis figurativa en Mesoamérica, la abstracción andina y la arquitectura monumental, entre tantos. Dicho esto, propongo enfocar nuestro análisis exclusivamente en la tendencia geometrizante, la cual fue percibida como un recurso despojado de significado.

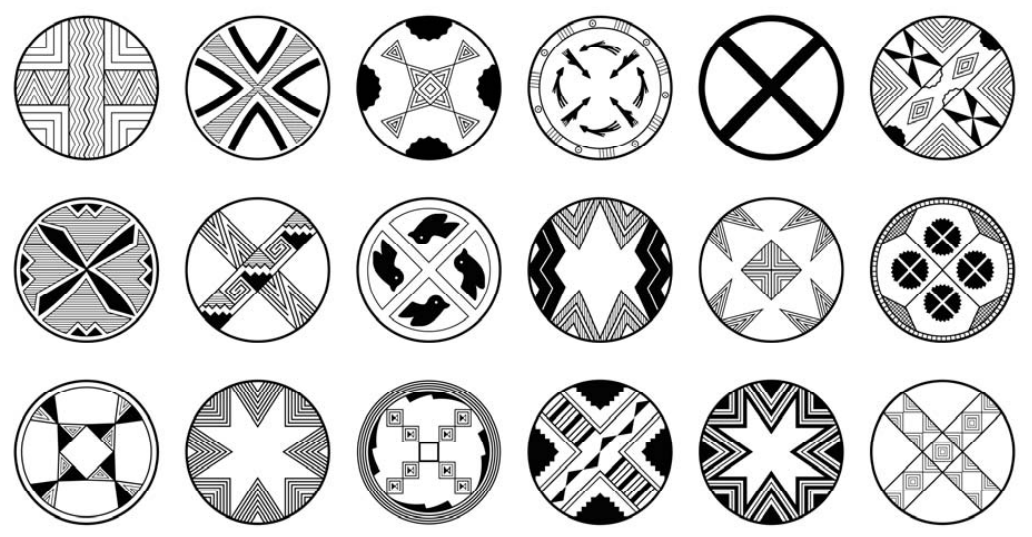

Figura 1. Selección de diseños precolombinos en la pintura cerámica en González (1975-76: 69-70). Reinterpretación digital, elaboración de Bruno Jara.

La figura 1 corresponde a una serie de ilustraciones recopiladas por Carlos González en su estudio sobre la pintura cerámica, en el cual nos muestra una amplia variedad de diseños indígenas del Chile precolombino ${ }^{10}$. Desentendiéndonos de las particularidades sociales y semióticas de cada uno de los diseños individuales, podemos determinar a simple vista una relación de semejanza. Consideradas en conjunto, las diferencias iconográficas de cada objetivación tienden a sintetizarse en lo que sigue: (1) diseños inscritos en una circunferencia; (2) por lo general, construidos a partir de líneas rectas; (3) desarrollo concéntrico de patrones lineales o abstractos; (4) preponderancia de un eje central que divide al círculo en secciones simétricas; (5) dichas áreas quedan determinadas según cuatro cuadrantes, los cuales rara vez presentan diferencias entre sí. Graficadas sobre distintos soportes, usualmente vasijas de barro, estas composiciones suponen la codificación simbólica de procesos rituales. Independientemente de sus especificidades, cada uno de estos diseños configura una representación de la armonía cósmica. En este

\footnotetext{
${ }^{9}$ Calabazas pintadas, cestería, tejidos, utensilios.

${ }^{10}$ Aunque el autor reúne más de treinta diseños, no especifica a qué culturas pertenecen cada uno de ellos. No obstante, por el texto sabemos que incluye las vasijas de Chañaral y los grafismos araucanos.
} 
sentido, la abstracción geométrica actuó como un medio para objetivar aquello que no tiene forma o materia definida: el cosmos carece de una referencia inmediata, es intrínsecamente irrepresentable.

El arte indígena esquiva el figurativismo porque, en gran parte, su objeto se encuentra vinculado con experiencias sociorreligiosas en sí mismas irrepresentables; por eso es fundamentalmente abstracto: al desentenderse de las exigencias de la denotación inmediata, se mueve mucho más por construcciones retóricas que por referencias directas (Escobar, 2008: 73).

El error de la plástica europea -considerar estos grafismos como ornamentación- originó una confusión en la cual la verdadera dimensión del objeto resultó alterada: "este conjunto es una unidad que exige una situación determinada por parte del espectador, como exigió una posición determinada al hombre que participó del rito o ceremonia que los involucraba" (González, 1975-76: 68). Desde el análisis mexicano, Paul Westheim indica que el arte prehispánico es un arte eminentemente religioso que aspira a asir lo visible y lo invisible mediante el pensamiento mítico-mágico: éste identifica la imagen de un objeto con el objeto mismo y no considera la representación como una mera imagen; según dicho pensamiento, la imagen tiene la misma realidad, las mismas propiedades de la deidad y, sobre todo, sus mismas virtudes mágicas (2006: 15). Así, "lo esencial es la creación de ese estado de alma -de ese encantamiento mágico- en que el creyente, sustraído a lo profano y terrestre, se siente elevado a la esfera de lo sobrenatural" (15). De ahí que la experiencia socioreligiosa se desplegara dentro de las composiciones cerámicas, dotando de sentido simbólico tanto al material donde se inscribían como a los individuos que se involucraron en sus usos o ceremonias. Nos queda clara, entonces, la impronta colectiva de estas formaciones culturales, las cuales contrastaban radicalmente con los preceptos renacentistas:

Las formas que se adhieren a un objeto, o los objetos mismos, no son, por lo tanto, meros caprichos o formulaciones arbitrarias del "artista". La cosa sacralizada, o el signo, llega a ser tal debido a su eficacia, a su capacidad de significar lo previsto, de actuar como un vehículo entre el hombre y lo superior a él (González, 1975-76: 66).

En primer lugar, este conjunto de formas desentonó de la mímesis europea en cuanto a la geometría simbólica o la síntesis figurativa que se graficaba sobre todo en la América surandina. En segunda instancia, la figura del artista, como poseedor individual de una destreza específica, quedó diluida dentro de una colectividad que no distinguió genios ni apellidos: el artista de América fue un sujeto plural, anónimo y partícipe activo de la sociedad en donde se instituyeron sus prácticas: su arte fue fruto de sus preocupaciones vitales o de sus relaciones con las divinidades, el más allá y el culto a sus antepasados (Gamboa, 1995: 78). En tercer lugar, las objetivaciones culturales de América no se distinguieron entre artesanías y artes mayores, es decir, no se realizó una categorización en cuanto a habilidades, 
sino que la jerarquía estuvo asociada al uso ritual y antropológico que se le otorgaba a la representación. Por último, mientras el arte renacentista se limitaba a construir una obra que se cerraba en su propio campo de enunciación, el arte prehispánico se caracterizó por la oscilación entre distintas instrumentalizaciones: una misma representación valía tanto para explicar la cosmovisión del universo como para calendarizar las temporadas del año, pronosticar los períodos de sembrío y cosecha, determinar el ciclo lunar, y profesar como sistema de escritura, entre otros. Esta pluralidad de atributos impidió considerar a las objetivaciones prehispánicas como formas puristas del arte, "cuya falta de reconocimiento se debía precisamente a su originalidad, a que eran formas propias, originadas por creencias y sociedades totalmente ajenas a la mentalidad occidental" (Gamboa, 1995: 85). Sin embargo, no propongo reducir su rugosidad de significados a una sola capa de interpretación, sino demarcar los criterios con los que deberían analizarse sus cualidades artísticas. Sobre este aspecto, Francisco Gallardo nos advierte asertivamente acerca del sinsentido que recae en extrapolar y reducir estas formaciones a un solo campo de enunciación. Gesto que, de todos modos, me parece igual de agresivo que el primer menosprecio ejercido por el conquistador frente a la cultura material de América, quinientos años atrás:

Si estas manifestaciones son obras de arte, datos científicos o patrimonio de alguien, no debería llevar a tantas polémicas. Difícilmente ante su historia podemos pretender definir lo que ellas son realmente, pues sabemos que, incluso en sus propios contextos de producción, circulación y consumo, tampoco fueron siempre la misma cosa (2016: 119-120).

Continuando, la figura 2 presenta una composición de volantines instalada por la artista chilena Magdalena Atria, en el marco de su exposición individual titulada Love and space. La muestra, abierta al público entre el 8 de agosto y el 13 de octubre del 2013 en el Museo de Artes Visuales (MAVI) de Santiago, exhibió un conjunto de obras realizadas a partir de materias diversas y de escasa tradición artística como la plasticina, la piedra y la totora. La consigna que se mantuvo a través de éstas nos remite a la conjunción de lo emocional con lo formal y de lo ideal con lo real. Entremedio de dichas variables, la artista detectó una posibilidad de acción en la que pretendió corporeizar un imaginario colectivo que, según su propuesta, había permanecido en la esfera de lo irrepresentable:

Desde hace varios años he desarrollado un trabajo visual en el que intento conectar el ámbito de lo ideal, de lo anhelado y de lo incorpóreo -expresado en la forma abstracta, muchas veces geométrica-con la dimensión vivencial y existencial de la cotidianeidad, con sus accidentes y su realidad concreta (MAVI, 2013).

Si superponemos la primera capa discursiva -aquella correspondiente al estudio de la pintura cerámica- por sobre el statement de Magdalena Atria que expusimos arriba, podemos detectar una contigüidad conceptual en la cual ambas 
objetivaciones, pese al distanciamiento temporal que las separa, logran encontrarse con relación al manejo geométrico como recurso idóneo para representar lo intangible. Ahora bien, incluso cuando la artista no expresa en esta instancia ninguna referencia directa hacia el imaginario prehispánico, podemos visualizar una correlación explícita entre las representaciones del cosmos precolombino (figura 1) y la instalación de los volantines (figuras 2 y 3).

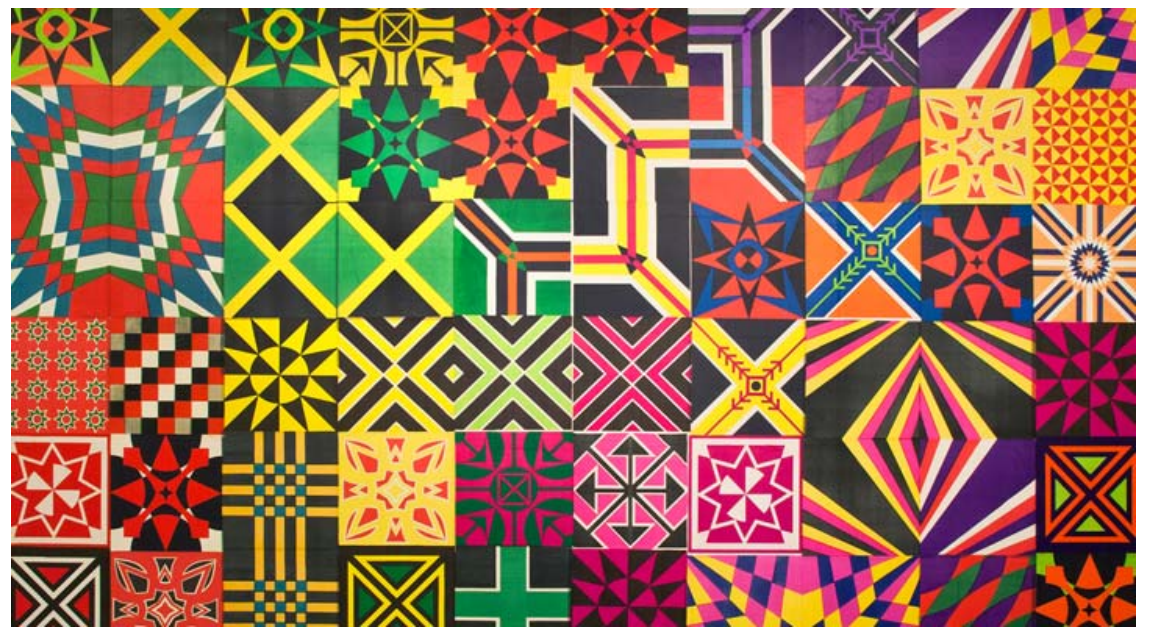

Figura 2. Magdalena Atria, Love and Space, volantines y engrudo, medidas variables. MAVI, 2013.

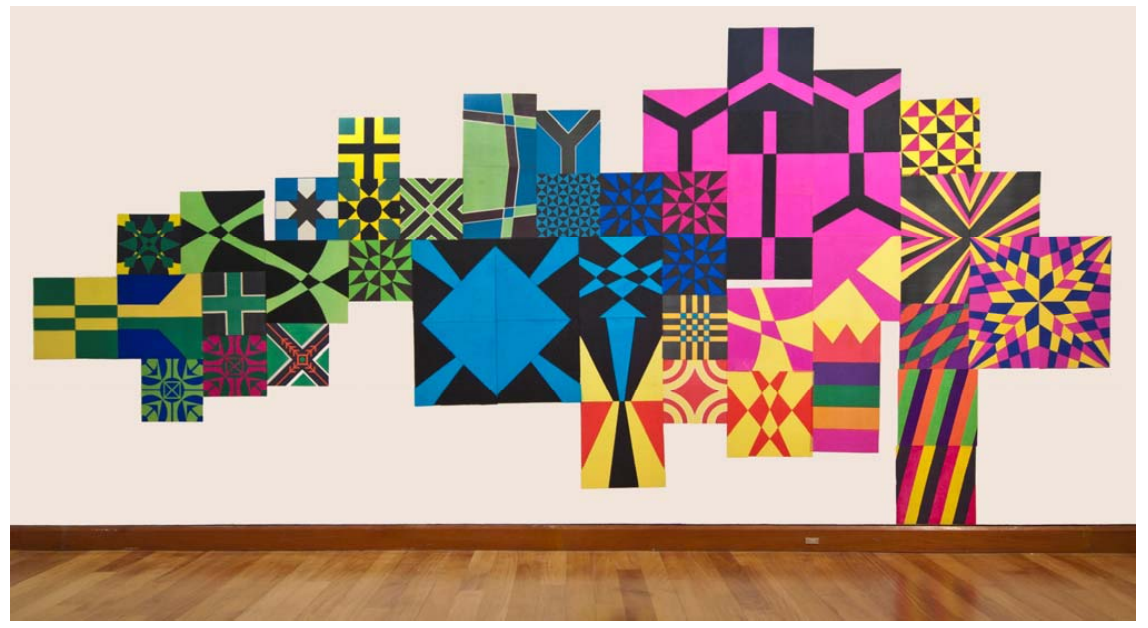

Figura 3. Magdalena Atria, Love and Space, volantines y engrudo, medidas variables. MAVI, 2013. 
Ambas composiciones intentan capturar, mediante la abstracción, los gestos de lo inefable y la raigambre social que implica la imaginación colectiva de un grupo. También a nivel iconográfico, las objetivaciones parecen continuar una misma ley de configuración: diseños geométricos distribuidos en un plano cuyo centro los divide, generalmente, en cuatro ejes equivalente entre $s^{11}$. A través del tratamiento gráfico del volantín, elemento insigne de las fiestas patrias chilenas, sospecho una intención por subvertir la dominación hegemónica que profesa el Estado sobre los pueblos nativos y las culturas populares. Según mi lectura, el volantín podría interpelar una celebración que esconde un proceso de independencia marcado por los mismos actos de violencia que vivenciaron los grupos autóctonos durante la Conquista.

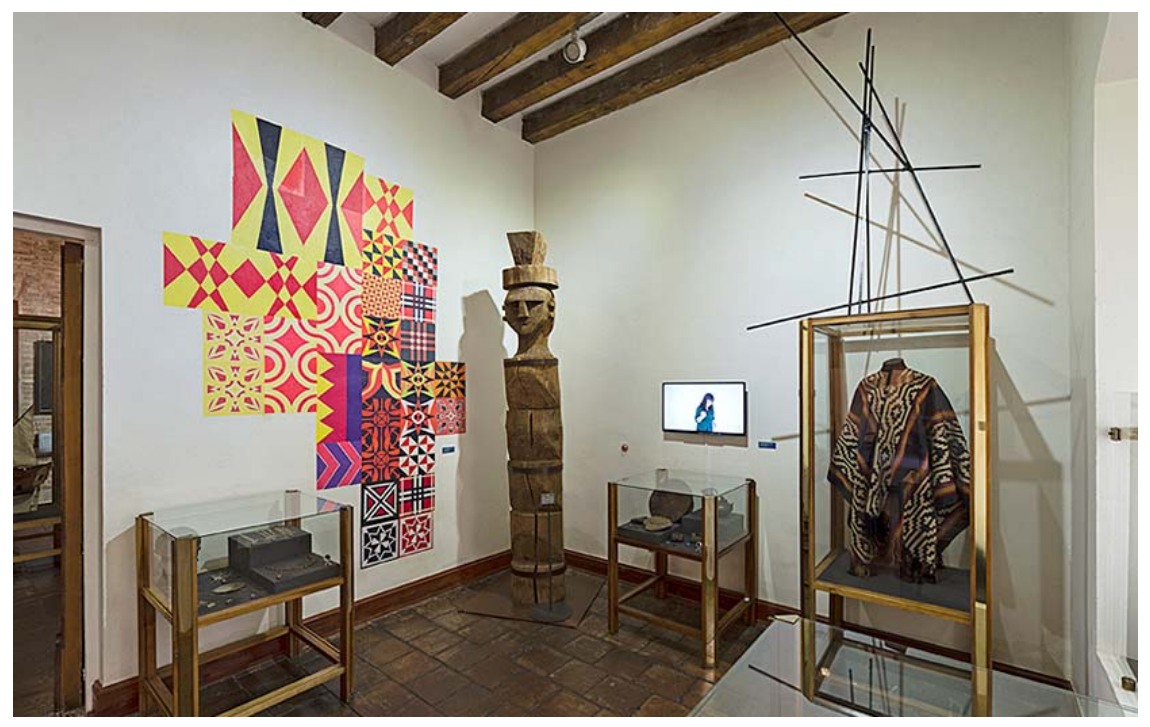

Figura 4. Magdalena Atria. "Un año de pájaros".

Volantines y engrudo, medidas variables (MNH, 2014: 32).

Luego, la figura 4 muestra una nueva propuesta del trabajo de Magdalena Atria, ahora emplazado dentro de la sala "Los primeros habitantes de Chile", del Museo Histórico Nacional (MHN). Esta nueva obra se enmarcó en el proyecto curatorial Efemérides. Fragmentos selectos de la historia reciente de Chile, convocatoria efectuada el año 2013. La intervención directa de las salas por parte de treinta y ocho artistas contemporáneos implicó una confrontación crítica en cuanto a la

11 Evidentemente, las diferencias cromáticas entre ambas objetivaciones deben ser tomadas en consideración al momento de realizar un análisis propiamente semiótico. 
comprensión del guión museológico, por tanto, de la narrativa oficial que se ofrece de la historia. De este modo, se plantearon preguntas atingentes a la representatividad de la historiografía y el reconocimiento legítimo de los relatos de extramuros. Según el curador Cristián Silva, se buscó "poner en tensión las múltiples conexiones entre memoria, identidad y patrimonio, desde la perspectiva que ofrecen las artes visuales contemporáneas" (MHN, 2014: 6).

En ese contexto, la obra de Magdalena Atria se expandió conceptualmente con relación a su trabajo precedente. Si bien en Love and space los contenidos de las obras circundaban un imaginario social que no refería explícitamente a la imaginería precolombina, en esta nueva propuesta la obra adquirió una clave de lectura concreta en torno a la problemática de la memoria prehispánica. Me parece distinguible mencionar que, pese a mostrar variaciones en cuanto a color y distribución, la nueva obra, en sí misma, no supuso un cambio significativo al momento de ser contrastada con la serie que hemos revisado arriba (figuras 2 y 3 ). Es más, la evocación cobra sentido a propósito del espacio en donde se instaura la obra y no necesariamente por las sutiles modificaciones de la representación. Así, montada dentro de la sala "Los primeros habitantes de Chile", la obra viene a denunciar aquella pluralidad de voces anónimas que han sido restituidas de la oficialidad, al momento de reconstruir la raíz genealógica de los pueblos originarios. La composición de volantines admite una interpretación memorística, una pugna, en la cual podemos vislumbrar el quejido incómodo de los grupos que todavía luchan, todos en simultáneo, por ocupar los espacios del reconocimiento público. Dentro del Museo, esto se ve claramente graficado en la oposición entre el imaginario araucano, apenas reconocido dentro de la memoria nacional, y la propuesta de la artista, montaje que carece de una identidad étnica específica. Vale decir, se expresa una tensión reivindicatoria entre la figura de lo oficial-admitido -la versión histórica de la nación-y una pluralidad de voces anónimas que coparticiparían de un "despertar comunitario por la patrimonialización de la memoria, que antepone la historia de las comunidades locales por sobre aquella que involucra a una sociedad entera" (Gallardo, 2016: 118). Imposible de categorizar o de vincular a un grupo particular, la obra nos sirve como una alegoría para entender los funcionamientos actuales del patrimonio precolombino: un gran conjunto de objetivaciones heterogéneas que, silenciadas por la oficialidad, batallan por restablecer, aunque sea en un ínfimo espacio, la facultad de enunciación de la cual se les privó.

Finalmente, me parece más que oportuno destacar la residencia de arte colaborativo Acción Monumenta, efectuada por el colectivo de arte Museo 
Internacional de Chile $(\mathrm{MICH})^{12}$ y la comunidad de Matilla ${ }^{13}$, entre fines de septiembre y mediados de diciembre del año 2016. La experiencia tuvo por objeto construir, en conjunto, un monumento a la diversidad cultural de la comunidad tarapaqueña, para valorar su memoria y promover el diálogo intercultural local (MICH, 2017).

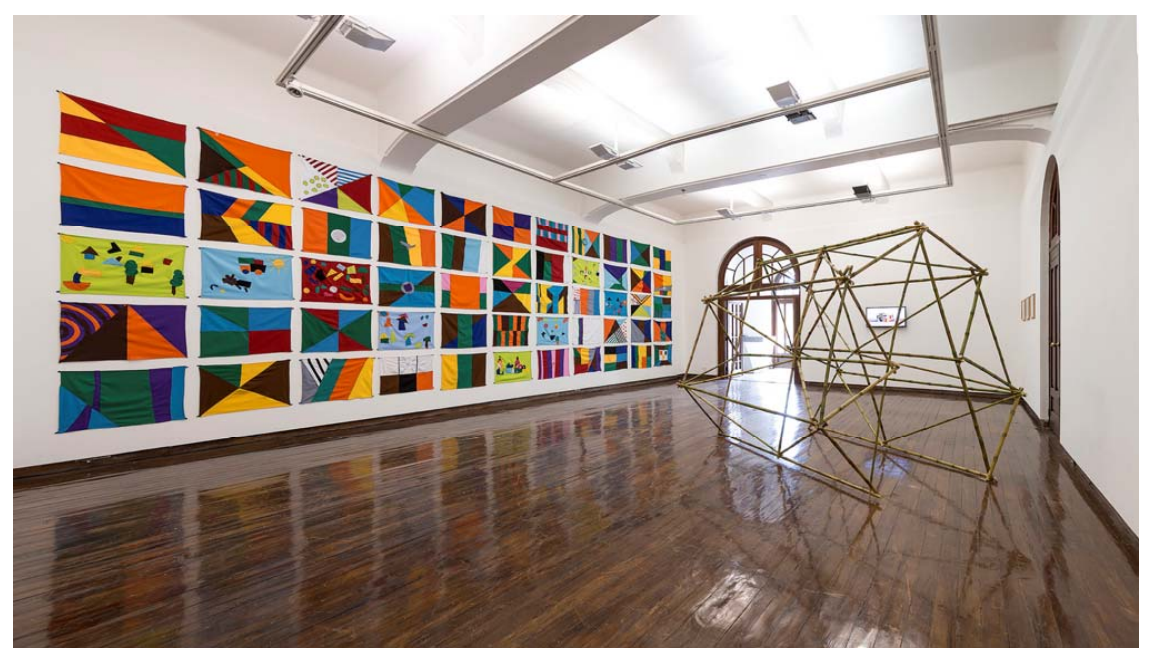

Figura 5. Colectivo MICH. Acción Monumenta. Galería Macchina, 2017. Imagen cortesía de los artistas.

El proyecto consistió en la aplicación de diversas metodologías de creación colectiva, cuyos resultados se articularon procesualmente, según un flujo constante entre las actividades del MICH y las respuestas de la comunidad; apuesta cuya operación dialógica logró hilvanar la realidad del paisaje árido con los distintos imaginarios sociales que emergieron del pueblo y sus habitantes. En las figuras 5, 6 y 7 vemos parte de la exhibición que se emplazó en la Galería Macchina entre el 29 de marzo y el 9 de mayo del año 2017. El montaje reunió los aspectos más relevantes de la investigación, agrupando banderas, dibujos, videos, fanzines e instalaciones que dieron cuenta de las distintas experiencias de la residencia. Junto con ello, el proyecto contempló la publicación del libro Acción Monumenta. Residencia de Arte Colaborativo del Colectivo de Arte MICH en Matilla, el cual recoge, además de los resultados, las bitácoras de los integrantes y sus respectivas reflexiones finales.

\footnotetext{
12 Integrantes del colectivo de arte MICH en Matilla: Simón Catalán, Juan Durán, Pilar Quinteros, Sebastián Riffo, Fernanda Vergara, Héctor Vergara.

${ }^{13}$ Comuna de Pica, Región de Tarapacá, Chile.
} 
Panambí n. 5 Valparaíso dic. 2017 ISSN 0719-630X. 9-32. DOI: 10.22370/panambi.2017.5.1037.

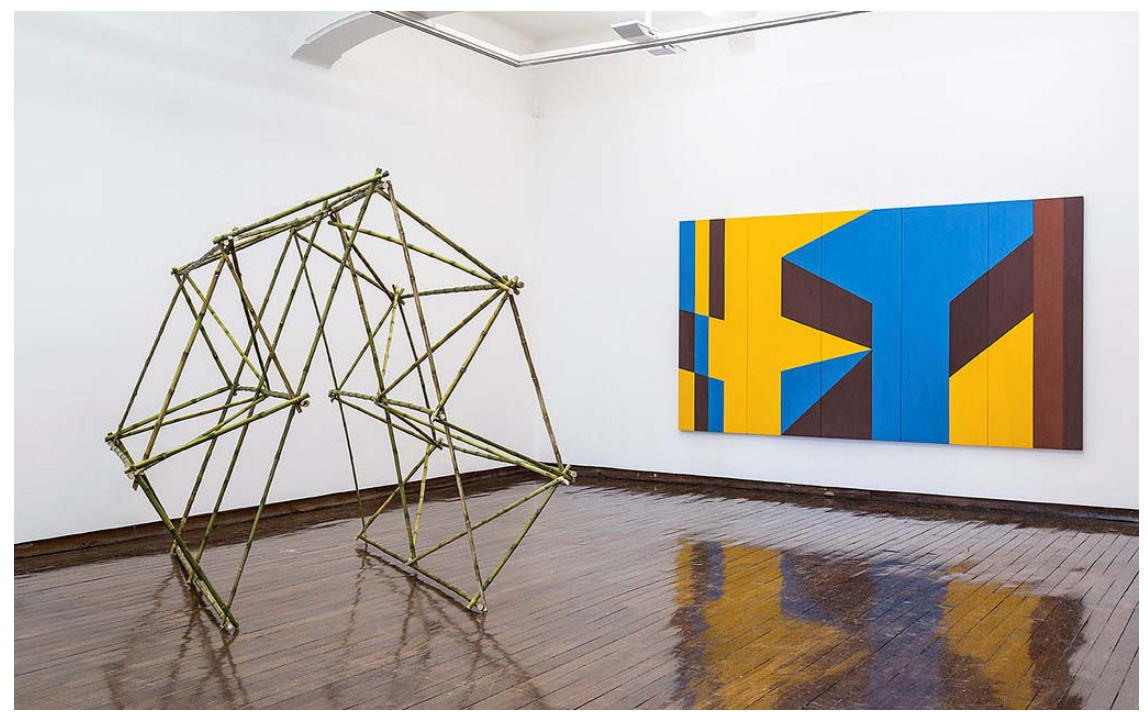

Figura 6. Colectivo MICH. Acción Monumenta. Galería Macchina, 2017. Imagen cortesía de los artistas.
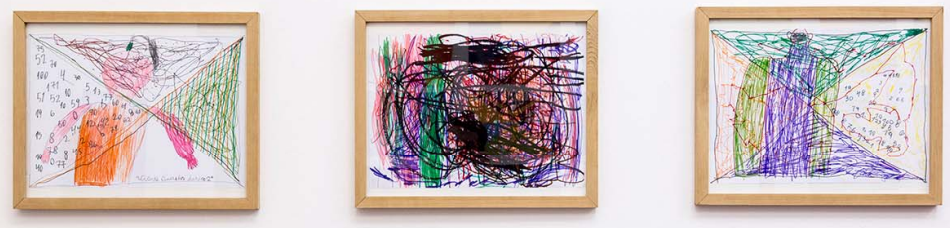

Figura 7. Colectivo MICH. Acción Monumenta. Galería Macchina, 2017. Imagen cortesía de los artistas. 
La residencia mantuvo una estructura concreta, aunque flexible, que partió con la exploración activa del lugar: recorridos por Matilla y Pica, entrevistas y diálogos con los habitantes y artistas locales, y una profunda inmersión sociocultural en lo cotidiano. Tras esto, el trabajo participativo propiamente tal: actividades y encuentros creativos en Pica, en la Escuela Nueva Extremadura de Matilla, en el Club de Cachimbo Matillano y en la plaza del pueblo. A ello siguió la fase de recopilación, la cual le permitió al colectivo visualizar el acervo simbólico y visual que se iba construyendo con las dinámicas, elemento que favoreció la toma de decisiones. Finalmente, en la fase analítica se establecieron relaciones y puntos de encuentro entre las distintas respuestas de la comunidad.

Uno de los principios más relevantes que enhebró el desarrollo de la residencia, fue que los ejercicios planteados no buscaron enseñar o corregir técnicas, tampoco instaurar conceptos pertinentes a la nomenclatura artística:

(los encuentros y actividades) eran instancias donde se ponía en valor la experiencia personal, la información que traemos con nosotros, y cómo podíamos mediar desde las artes visuales este conocimiento. A través de estos ejercicios pudimos rescatar los colores y formas de Matilla, las historias de los niños y niñas de la zona, los hitos patrimoniales que más les interesaban a los adultos, las palabras que mejor identificaban la zona, etc. (MICH, 2017: 49).

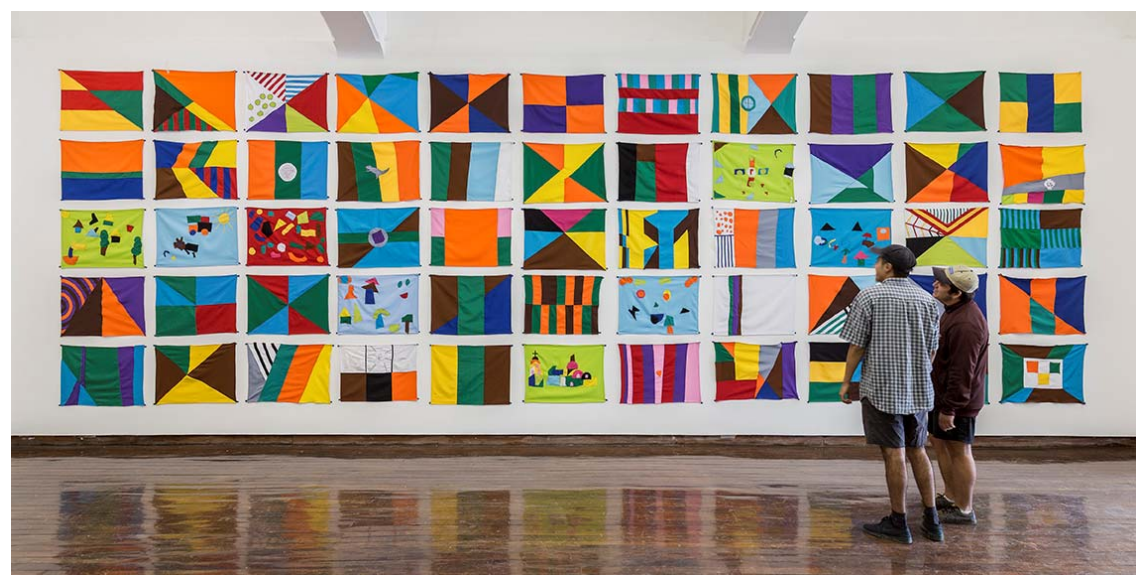

Figura 8. Colectivo MICH. Acción Monumenta. Galería Macchina, 2017. Imagen cortesía de los artistas.

Así, la figura 8 muestra las banderas que surgieron de las actividades: buscando extraer intuitivamente la riqueza cultural de la región, se invitó a la comunidad a representar la identidad del pueblo mediante el dibujo. A partir de coordenadas preestablecidas, los dibujantes seguían instrucciones específicas y restrictivas con 
las que iban armando un conjunto de signos que, pese a las limitaciones, respondían a sus propias motivaciones, gustos o parámetros de significación. Por ejemplo, en la figura 9 vemos una selección de los dibujos realizados por los estudiantes, quienes entregaron una amplitud de imágenes que destacaban por la pluralidad de vistas sobre un mismo territorio: "No estábamos creando sólo una bandera de Matilla, estábamos sacando a la luz las múltiples y diversas banderas de Matilla" (2017: 64).

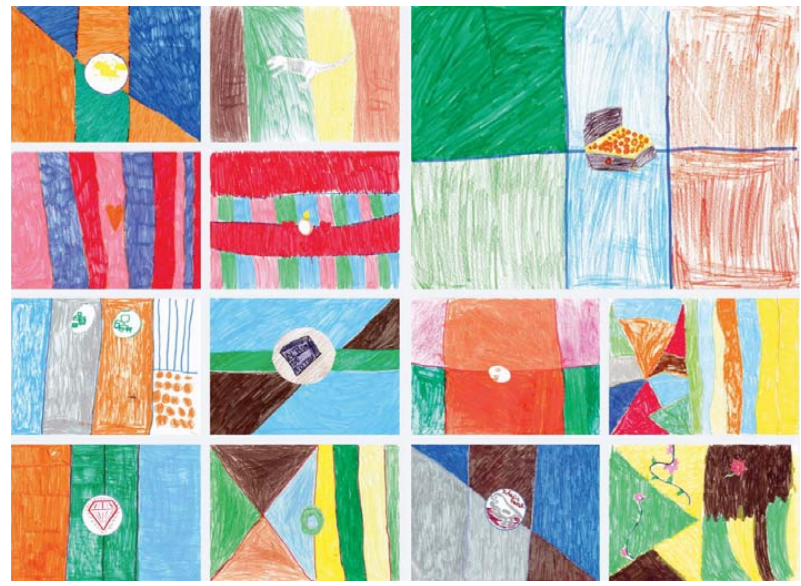

Figura 9. Selección de dibujos de los estudiantes de la Escuela Nueva Extremadura de Matilla en el contexto de la Acción Monumenta de MICH (2017: 68, 74).

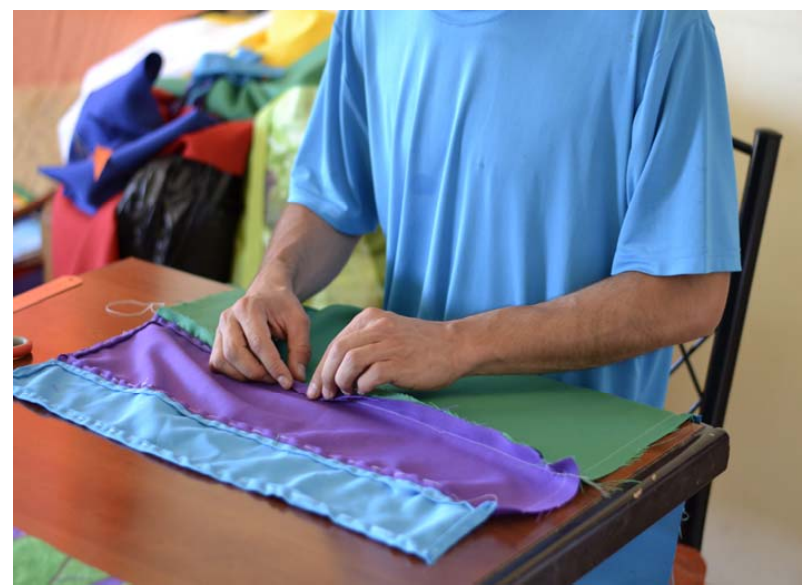

Figura 10. Traspaso de dibujo a textil, proceso en el contexto de Acción Monumenta. Imagen cortesía de MICH. 


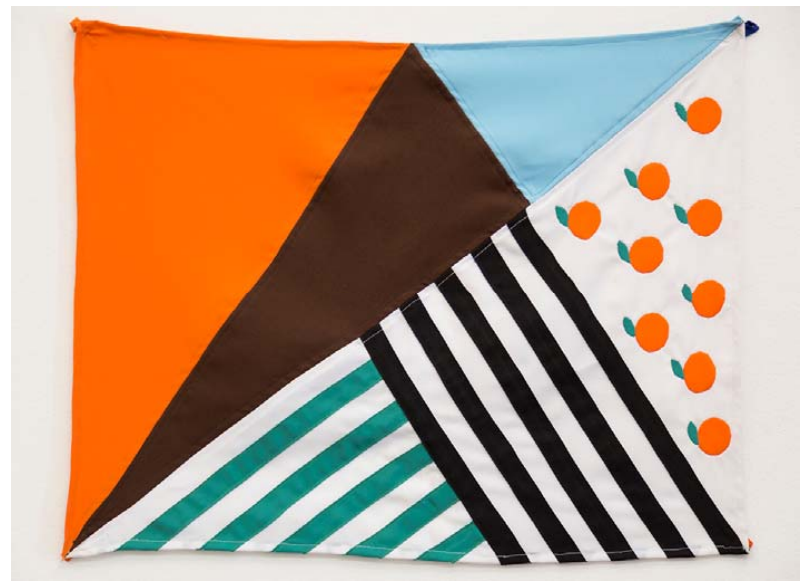

Figura 11. Traspaso de dibujo a textil, resultado. Acción Monumenta. Imagen cortesía de MICH.

La etapa final de la residencia implicó la traducción textil de los dibujos (figuras 10 y 11). Tras un arduo trabajo e intentando traspasar fielmente los gestos originales, el MICH consiguió producir más de cincuenta banderas. Posteriormente, el colectivo instaló las banderas en el desierto (figura 12) y en los espacios públicos de la comunidad: devolvió las imágenes concretas al entorno desde donde fueron pensadas. Aquí se llevó a cabo una votación en la que los estudiantes escogieron la bandera que mejor los representaba (figura 13).

Al interpretar la propuesta del $\mathrm{MICH}$, mi primera reflexión gira en torno a la bandera y sus significados: un medio que vehiculiza el sentido de la identidad y la unión. La bandera promueve en tanto que encarna los valores de un imaginario representativo, totalizante. Mientras su luz es la patria, la sombra de la bandera es el peso de todos los emblemas que no caben dentro de su margen rectangular: una manta de silencio que obscurece las voces incómodas, estratégicamente olvidadas. En este sentido, Acción Monumenta ilustra la identidad de Matilla mediante una operación totalmente contraria: es la sumatoria de ecos y memorias individuales la que escenifica un monumento. La propuesta del $\mathrm{MICH}$ interviene en la comprensión de la bandera al subvertir sus funciones: no se utiliza como defensa única de la propiedad, asume que en un paisaje existen encuentros interculturales que rebasan la artificialidad de las fronteras. El imaginario social es trazado colaborativamente, según distintos enfoques y propuestas. Aún cuando finalmente se escogió una bandera como insignia de Matilla, el conjunto prima por sobre la autonomía de la imagen aislada. La potencia está allí, en el macrorelato de afectividades cruzadas: experiencias que lograron materializar lo incorpóreo, la autoimagen del pueblo, mediante un mapeo visual de las subjetividades. 


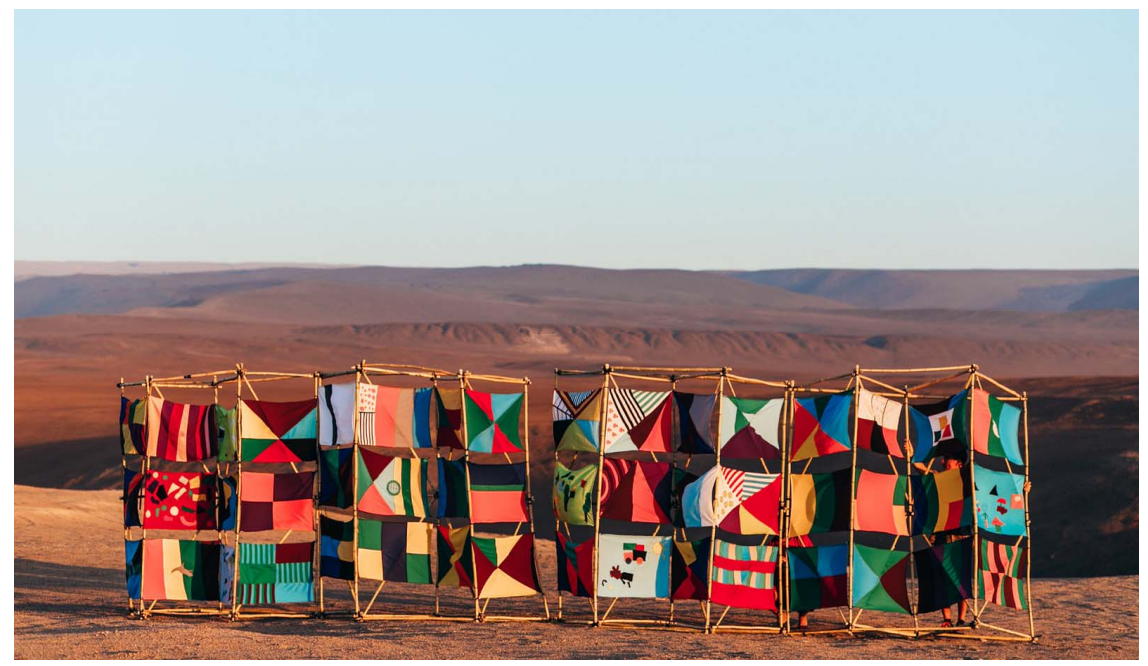

Figura 12. Instalación de banderas en el desierto. Imagen cortesía de MICH.

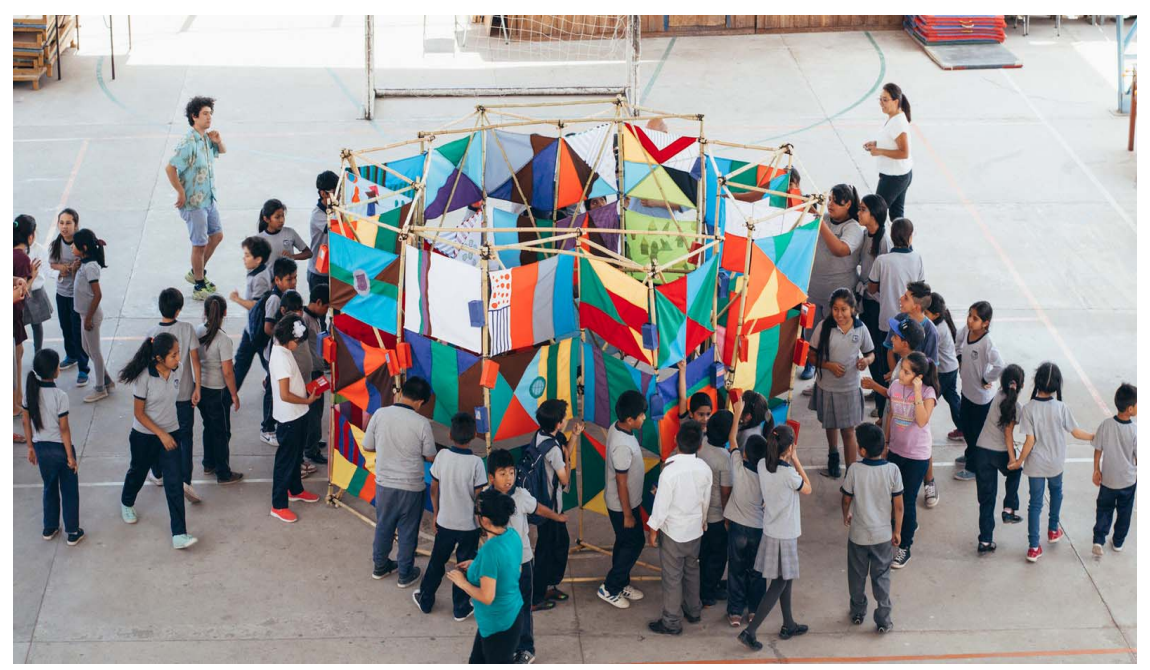

Figura 13. Elección de la bandera representativa de Matilla. Imagen cortesía de MICH.

En retrospectiva, la propuesta del $\mathrm{MICH}$ se enlaza con las obras de Magdalena Atria (figuras 2, 3 y 4) desde un ámbito más bien formal. Y, pese a que los distintos ejercicios de Acción Monumenta suponían diferentes pautas -realizados por niños o adultos; desde lo abstracto a lo figurativo, o al revés; procesos individuales o colectivos-, lo cierto es que hay coincidencias entre ambos planteamientos que 
saltan a la vista: (1) representaciones múltiples; (2) preponderancia de la abstracción geométrica; (3) composiciones que tienden a la simetría axial en torno a un eje central; (4) colores en bloque, saturados y brillantes; (5) pregnancia de texturas y ritmos visuales; (6) montaje de amplia extensión, elaborado a partir de unidades independientes. Según estas mismas conexiones, aunque omitiendo las diferencias cromáticas y el montaje, las pinturas cerámicas del Chile precolombino (figura 1) también encuentran su resonancia en el trabajo del $\mathrm{MICH}$.

Desde una segunda capa de lectura, existe una convergencia entre los soportes escogidos: mientras la pintura precolombina se inscribía en objetos de uso cotidiano como vasijas o cántaros, las obras contemporáneas aquí presentes también utilizan elementos arraigados a la imaginación cotidiana de Chile: el volantín, de corte festivo, y la bandera, de corte institucional. No obstante, ambos objetos son resignificados y desplazados de su función de uso habitual con el objeto de elaborar nuevos sentidos. Los volantines descubren un tratamiento visual que hace resonancia inmediata con la abstracción geométrica de América prehispánica. A la vez, la bandera diversifica sus límites, aceptando un sistema de formas en vez de la univocidad hegemónica que presume una imagen representativa. En tercer lugar, las tres propuestas comparecen en un propósito común: corporeizar lo irrepresentable, los ideales y la ensoñación. Mientras las objetivaciones precolombinas se enfocaron en la armonía cósmica, las propuestas contemporáneas intentan asir los imaginarios sociales mediante la descontextualización de los objetos y materiales, en el caso de Magdalena Atria, y a través del trabajo participativo, en el caso del $\mathrm{MICH}$.

Para terminar, más allá de los paralelismos, quisiera destacar aquellos ecos precolombinos que sólo están presentes en Acción Monumenta. En primer lugar, la autoría de la obra está diluida entre los participantes: los artistas del $\mathrm{MICH}$ más bien gestionaron y promovieron el trabajo, que devino del pueblo mismo. Como hemos visto, este ámbito recuerda a las objetivaciones prehispánicas anónimas o colectivas. Luego, tanto el inicio como el cierre de la residencia estuvieron constantemente abiertos a la comunidad, emplazándose en lugares públicos e invitando continuamente a la participación. En este sentido, vinculamos su alcance con los usos sociales y simbólicos del arte precolombino. Así también, las instancias mismas del dibujo podrían ser interpretadas como una suerte de rito contemporáneo: la proyección de las banderas dota de sentido no sólo a la imagen resultante, sino también al devenir memorioso que se desencadena de dicha experiencia. Los encuentros creativos entretejen vínculos afectivos, conectan a los integrantes bajo un mismo propósito en donde cada una de sus individualidades fundamenta la composición global. La memoria colectiva se entrecruza en un mismo instante con la memoria cultural: hacen eco de los sonidos de una historia local, de una memoria visual, y de los ritmos que se cultivan en la tierra. 


\section{Conclusión}

En este estudio nos hemos enfocado en identificar ciertas trazas que rememoran tiempos pretéritos: alusiones concretas de una aproximación distinta al arte. Tras el estudio, descubrimos que la posibilidad de encuentro entre lo contemporáneo y lo prehispánico no sólo es efectiva, sino que, además, se filtra entre procesos que no necesariamente quieren remitir al pasado. Así, advertimos un mecanismo para comprender el acervo prehispánico más allá de la historiografía: una posición actuante en la que comparecemos de manera intuitiva ante metodologías y resoluciones estéticas similares.

Llegados a este punto, es necesario recordar que este artículo se planteó como un ejercicio de recomposición simbólica: de más está señalar que la amplitud de su alcance rebasa un solo escrito. De este modo, no nos sorprenderíamos al encontrar, aplicando la misma metodología, trazas precolombinas en un campo mucho más amplio al de la disciplina artística: el diseño, la literatura, la música, la indumentaria. O bien, desde otro ángulo, podríamos recuperar las propuestas de artistas contemporáneos que aluden directamente a estas temáticas. Sólo por mencionar algunos: Nadín Ospina, Sebastián Calfuqueo, Demian Schoff y la intervención de Josefina Guilisasti en el Museo de Arte Precolombino, entre tantos.

Ahora bien, como todo ejercicio de memoria, el anterior no quiso ser interpretado como un instrumento rígido de análisis. Tampoco pretendió alcanzar la universalidad a partir de la configuración de una microhistoria. Por el contrario, el objetivo de este artículo fue el de recuperar las subjetividades, los ecos y los matices de un patrimonio cultural que se resiste a perecer: animar las resonancias de una imaginación social intercultural. Finalmente, se quiso defender un lugar de acción para estos imaginarios prehispánicos, trágicamente escondidos tras una visión reductiva y aplanadora, en la que apenas distinguimos formaciones culturales que no "alcanzan a ser arte", que son otra cosa, o cuya interpretación se nos escapa de las manos.

\section{Referencias}

Asmman, J., \& Czaplicka, J. (1995). Collective Memory and Cultural Identity. New German Critique (65), 125-133.

Atria, M. (2013, agosto). Love and Space (exposición). Santiago: MAVI, Museo de Artes Visuales. Recuperado el 9 de marzo del 2017 de http://mavi.cl/expos/love-and-space/.

Castoriadis, C. (1997). El imaginario social instituyente. Zona Erógena (35), 1-9.

Cruz, I. (1986). Arte y sociedad en Chile: 1550-1650. Santiago: UC. 
Escobar, T. (2008). El mito del arte y el mito del pueblo. Cuestiones sobre arte popular. Santiago: Metales Pesados.

(2013). Arte indígena: el desafío de lo universal. Revista Casa (271), 318.

Gallardo, F. (2016). Colecciones precolombinas y sus transmutaciones culturales. En M. Alvarado, L. Campos, F. Gallardo, J. Gómez, F. Kalazich, F. Martínez, y otros, Patrimonio y pueblos indígenas. Reflexiones desde una perspectiva interdisciplinaria e intercultural (págs. 109-120). Santiago: Pehuén.

Gamboa, P. (1995). Arte precolombino, arte moderno y arte latinoamericano. Ensayos: Historia y teoría del arte (1), 75-102.

González, C. (1975-76). Un signo pintado en la cerámica chilena. Formulación de una hipótesis. Aisthesis, La pintura y sus problemas en Chile (9), 65-82.

Gruzinski, S. (1994). La guerra de las imágenes. De Cristóbal colón a "Blade Runner" (1492-2019). México: FCE.

Halbwachs, M. (1998). Memoria colectiva y memoria histórica. Revista Sociedad (12), 209-219.

Méndez, L. (2006). ¿¿Quiénes dictan las reglas del arte? De la privatización de artes y artistas no occidentales al mutuo reconocimiento: un desafío político y artístico pendiente. Artes la Revista, 6 (11), 24-34.

Moraña, M. (2014). Inscripciones críticas. Ensayos sobre cultura latinoamericana (1a edición ed.). Santiago: Cuarto Propio.

MHN, Museo Histórico Nacional (2014). Efemérides. Fragmentos selectos de la historia reciente de Chile. Santiago: DIBAM.

$\mathrm{MICH}$, Museo Internacional de Chile (2017). Acción Monumenta. Residencia de Arte Colaborativo del Colectivo de Arte MICH en Matilla (catálogo). Valparaíso: $\mathrm{MICH}$.

Rothberg, M. (2009). Multidirectional Memory: Remembering the Holocaust in the Age of Decolonization. Stanford, CA: Stanford University Press.

Sánchez, E. (1989). El arte precolombino. Madrid: Historia 16.

Shiner, L. (2004). La invención del arte. Una historia cultural. (E. H. Julibert, Trad.) Barcelona: Paidós.

Tatarkiewicz, W. (2001). Historia de seis ideas. Madrid: Tecnos.

Westheim, P. (2006). Arte, religión y sociedad. México: FCE. 